\title{
A NOÇÃO DE TEXTO NA SEMIÓTICA
}

\author{
José Luiz Fiorin
}

RESUMO: Ce travail présente la notion de texte avec laquelle travaille la Sémiotique d'origine française. Le texte à l'interieur de cette théorie est conçu comme une totalité de sens. Cet objet de signification est engendré par un parcours génératif qui va du plus simple au plus complexe, du plus abstrait au plus concret. Ce parcours est constitué de trois niveaux superposés: les structures fondamentales, les structures narratives et les structures discursives. Chaque niveau comporte une composante syntaxique et une composante sémantique. Chacun reprend le précédent et, par un processus d'enrichissement sémantique, le concrétise. La textualisation est la jonction du plan du contenu produit du parcours génératif et d'un plan de l'expression.

PALAVRAS-CHAVE: texto, discurso, semiótica, percurso gerativo, intradiscursividade, interdiscursividade.

As diferentes teorias do discurso, que surgiram a partir do momento em que a Lingüística, depois de ter como objetos teóricos o sistema e a competência, começa a preocupar-se com fatos que não estavam abarcados por eles, como, por exemplo, o uso lingüístico e as relações da utilização concreta da linguagem com o contexto sociohistórico, trabalharam basicamente com dois conceitos distintos de texto. Algumas conceberam-no como um objeto de significação; outras, como um objeto histórico. Não estamos aqui nos referindo aos conceitos presentes nas profissões de fé que costumam preceder o trabalho efetivo de teorização e análise, mas àqueles que se depreendem da análise rigorosa da teoria e da prática analítica, uma vez que, nas postulações de princípios, nenhuma teoria do discurso deixa de afirmar que o texto é um objeto, ao mesmo tempo, lingüístico e histórico.

Dar ênfase ao conceito de que o texto é um objeto de significação implica considerá-lo um todo de sentido, dotado de uma organização específica, diferente da da frase. Isso significa, portanto, dar relevo especial ao exame dos procedimentos e mecanismos que o estruturam, que o tecem como uma totalidade de sentido. Cabe lembrar que a palavra texto provém do verbo latino texo, is, texui, textum, texere, que quer dizer tecer. Da mesma forma que um tecido não é um 
amontoado desorganizado de fios, o texto não é um amontoado de frases, nem uma grande frase. Tem ele uma estrutura, que garante que o sentido seja apreendido em sua globalidade, que o significado de cada uma de suas partes dependa do todo.

Dar destaque à noção de que o texto é um objeto histórico leva a preocupar-se primordialmente com a formação ideológica de que ele é expressão, com as relações polêmicas que, numa sociedade dividida em classes, estão na base da constituição das diferentes formações discursivas.

Antigamente, dizia-se que as teorias que trabalhavam com o primeiro conceito faziam uma análise interna do texto, as que usavam o segundo faziam uma análise externa. Essa terminologia é muito ruim, porque deixa entrever que aquelas só se ocupam do aspecto lingüístico, enquanto estas só têm olhos para o extralingüístico. Na verdade, cada uma ressalta um aspecto da constituição do sentido e, portanto, são ambas teorias linguísticas. As primeiras acentuam os mecanismos intradiscursivos e as segundas, os interdiscursivos. Vale ressaltar que estamos falando em predominância de interesse por um dado aspecto e não em exclusividade.

Durante muito tempo, partidários de uma ou de outra teoria trocaram uma série de acusações. Os que se ocupavam preponderantemente dos aspectos intradiscursivos foram tachados de reducionistas, dizia-se que eles ignoravam a História, que tinham uma visão empobrecedora do texto. Por outro lado, dizia-se que os que trabalhavam predominantemente com as relações interdiscursivas eram cegos para os mecanismos de estruturação do texto, não reconheciam a especificidade lingüística do discurso. $\mathrm{Na}$ verdade, as desconfianças mútuas não precisariam existir, já que, de um lado, não se pode exigir que uma teoria explique fatos que estão fora de seu escopo explicativo; de outro, as teorias do discurso, ao ressaltar os mecanismos intradiscursivos ou os interdiscursivos, estão trabalhando com aspectos complementares da textualização e não com ângulos excludentes na abordagem do uso lingüístico.

A Semiótica francesa ${ }^{1}$, embora não ignore que o texto seja um objeto histórico (cf., por exemplo, GREIMAS, 1976, p.237-239), dá ênfase ao conceito de texto como objeto de significação e, por conseguinte, preocupa-se fundamentalmente em estudar os mecanismos que engendram o texto, que o constituem como uma totalidade de sentido.

Concebe-se como uma teoria gerativa, sintagmática e geral. E uma teoria sintagmática, porque seu escopo é estudar a produção e a interpretação dos textos. É geral, porque se interessa por qualquer tipo de texto, independentemente de sua manifestação. Postula que o conteúdo pode ser analisado separadamente da expressão, uma vez que o mesmo conteúdo pode ser veiculado por diferentes planos de expressão (por exemplo, uma negativa pode ser manifestada pela palavra

\footnotetext{
${ }^{1}$ Lembramos que há pelo menos três grandes teorias semióticas: uma que se elabora nos Estados Unidos e se constitui em tomo da obra de Charles Sanders Peirce; uma que se organiza na França e se constrói a partir da obra de Algirdas Julien Greimas; uma que se desenvolve na Rússia e se estabelece a partir da obra de Iuri Lotman. Neste texto, quando falarmos em Semiótica, estaremos referindo-nos à francesa. 
não ou por um gesto da cabeça ou do indicador). É, por conseguinte, uma teoria geral dos textos, quer se manifestem verbalmente, visualmente, por uma combinação de planos de expressão visual e verbal, etc. Num primeiro momento da análise, faz abstração da manifestação, para examinar o plano do conteúdo e só depois vai estudar as especificidades da expressão e sua relação com o significado. É uma teoria gerativa, porque concebe o processo de produção do texto como um percurso gerativo, que vai do mais simples e abstrato ao mais complexo e concreto, num processo de enriquecimento semântico. Isso significa que vê o texto como um conjunto de níveis de invariância crescente, cada um dos quais suscetível de uma representação metalingüística adequada. $O$ percurso gerativo de sentido não tem um estatuto ontológico, ou seja, não se afirma que o falante na produção do texto passe de um patamar ao outro num processo de complexificação semântica. Constitui ele um simulacro metodológico, para explicar o processo de entendimento, em que o leitor precisa fazer abstrações a partir da superfície do texto, para poder entendê-lo.

O percurso gerativo é constituído de três patamares: as estruturas fundamentais, as estruturas narrativas e as estruturas discursivas. Vale relembrar que estamos no domínio do conteúdo. As estruturas discursivas serão manifestadas como texto, quando se unirem a um plano de expressão no nível da manifestação. Cada um dos níveis do percurso tem uma sintaxe e uma semântica.

$\mathrm{Na}$ Gramática tradicional a sintaxe opõe-se à morfologia. Esta ocupa-se da formação das palavras e da expressão das categorias gramaticais por morfemas; aquela, da combinação de palavras para formar orações e de orações, para constituir períodos. Na Semiótica, a sintaxe contrapõe-se à semântica. Aquela é o conjunto de mecanismos que ordena os conteúdos; esta, os conteúdos investidos nos arranjos sintáticos. Observe-se, no entanto, que não se trata de uma sintaxe puramente formal, ou seja, não se opõem sintaxe e semântica como o que não é dotado de significado e o que tem significado. Um arranjo sintático é dotado de sentido. Por conseguinte, a distinção entre esses dois componentes reside no fato de que a semântica têm uma autonomia maior do que a sintaxe, o que significa que se podem investir diferentes conteúdos semânticos na mesma estrutura sintática.

Analisemos agora cada um dos patamares do percurso gerativo de sentido. O nível fundamental compreende a(s) categoria(s) semântica(s) que ordena(m), de maneira mais geral, os diferentes conteúdos do texto. Uma categoria semântica é uma oposição tal que $a$ vs. $b$. Podem-se investir nessa relação oposições como vida vs. morte, natureza vs. cultura, etc. Negando-se cada um dos termos da oposição, teremos não $a$ vs. não $b$. Os termos $a$ vs. $b$ mantêm entre si uma relação de contrariedade. A mesma coisa ocorre com os termos não $a$ vs. não $b$. Entre $a$ e não $a$ e $b$ e não $b$ há uma relação de contraditoriedade. Ademais, não $a$ mantém com $b$, assim como não $b \operatorname{com} a$, uma relação de implicação. Os termos que mantêm entre si uma relação de contrariedade podem manifestar-se unidos. Teremos um termo complexo, quando houver uma relação $a+b$; e um termo neutro, quando se estabelecer a união de não $a$ com não $b$. Esse conjunto de relações é muito 
importante, para analisar a especificidade de alguns textos, cuja sintaxe fundamental se caracteriza pela presença de termos complexos ou neutros. É o caso, por exemplo, do mito. Mircea Eliade dizia que ele é a coincidentia oppositorum. Ora, se analisarmos seus mecanismos de estruturação do sentido, veremos que ele se define por operar com termos que unem opostos, ou seja, com termos que englobam elementos semânticos contrários. O mito grego do andrógino, por exemplo, conta que esse ser reunia a masculinidade e a feminilidade. No âmbito da mitologia cristã, Cristo junta a divindade e a humanidade; os anjos englobam a não humanidade e a não divindade; a Virgem Maria articula a maternidade e a virgindade.

Essa categoria semântica do nível fundamental é, então, o elemento mais simples e abstrato de ordenamento dos múltiplos conteúdos do texto. O discurso ecologista articula-se em torno da oposição semântica /civilização/ vs. /natureza/. Estabelecer a categoria semântica de base não é, porém, o objetivo último da análise. É apenas apreender a articulação mais geral do texto. Para compreender, no entanto, toda a sua complexidade é preciso ir remontando aos níveis mais concretos e complexos do percurso.

Ainda no nível fundamental, os elementos em oposição transformam-se em valores. Isso é feito sobremodalizando-os com um traço de positividade ou negatividade, ou em termos mais precisos, com os traços /euforia/ e /disforia/. Dois textos podem, por exemplo, trabalhar com a mesma categoria semântica, mas axiologizá-la diferententemente e isso vai produzir discursos completamente distintos. Poderíamos, por exemplo, dizer que o discurso dos ecologistas sobre a Amazônia e o do governador Gilberto Mestrinho sobre a mesma questão operam com a mesma categoria semântica /civilização/ vs. /natureza/. Entretanto, enquanto aqueles consideram o primeiro termo da oposição negativo e o segundo positivo, este faz exatamente o contrário.

Passemos agora ao segundo patamar: as estruturas narrativas. Uma narrativa mínima define-se como uma transformação de estado. Este organiza-se da seguinte forma: um sujeito está em relação de conjunção ou de disjunção com um objeto. Temos, pois, dois tipos de estado: um disjunto e um conjunto. Quando dizemos Pedro é rico, temos um sujeito Pedro em relação de conjunção com um objeto riqueza. Quando afirmamos Pedro não é rico, temos um sujeito Pedro em relação de disjunção com um objeto riqueza. A transformação é, por conseguinte, a mudança da relação entre sujeito e objeto. Se há dois tipos de objetos, as transformações possíveis serão também duas: de um estado inicial conjunto para um estado final disjunto e de um estado inicial disjunto para um estado final conjunto. Assim, o pequeno texto Um faxineiro de São Paulo ganhou um milhão de dólares na Sena é uma narrativa, porque contém uma transformação de um estado inicial disjunto em que o sujeito faxineiro estava em disjunção com a riqueza para um estado final em que o mesmo sujeito está em conjunção com o objeto.

As transformações narrativas articulam-se numa sequiência canônica, assim chamada, porque, de um lado, revela a dimensão sintagmática da narrativa e, 
de outro, mostra as fases obrigatoriamente presentes no simulacro da ação do homem no mundo, que é a narrativa. A primeira fase é a manipulação. Nela, um sujeito transmite a outro um querer e/ou um dever. Essa fase pode ser concretizada como um pedido, uma súplica, uma ordem, etc. Temos, por exemplo, uma manipulação por provocação, quando o manipulador diz ao manipulado que ele é incapaz de realizar uma ação, esperando que, como reação, ele a execute com vistas a provar que é perfeitamente capaz de fazê-la. A segunda fase é a da competência. Nela, um sujeito atribui a outro um saber e um poder fazer. Quando, num conto maravilhoso, uma fada dá a um príncipe um objeto mágico, que lhe permitirá realizar uma ação extraordinária, está dando-lhe um poder fazer, figurativizado pelo referido objeto mágico. A terceira fase é a performance. Nela, ocorre a transformação principal da narrativa. Num conto de fadas em que a princesa foi raptada pelo dragão, a performance será a libertação da princesa. A última fase é a da sanção. Temos dois tipos de sanções, a cognitiva e a pragmática. Aquela é o reconhecimento por um sujeito de que a performance de fato ocorreu. Em muitos textos, essa fase é muito importante, porque é nela que as mentiras são desmascaradas, os segredos são desvelados, etc. A sanção pragmática pode ou não ocorrer. Pode ser um prêmio ou um castigo. Na chamada narrativa conservadora, porque tem a finalidade de reiterar os valores colocados na fase da manipulação, os bons são premiados e os maus castigados. Já numa novela como Justine, de Sade, cada vez que a personagem age segundo os ditames da moral cristã, recebe um castigo.

Essas fases mantêm entre si uma relação de implicação recíproca. Com efeito, se se reconhece que algo foi realizado, é porque efetivamente o foi ou, ao menos, parece ter sido. Para que um sujeito possa executar uma ação, é preciso que ele saiba e possa fazê-lo, isto é, seja competente para isso, e, ao mesmo tempo, queira e/ou deva fazê-lo.

A seqüência canônica não é uma fôrma onde se faz caber a narrativa. Ao contrário, inúmeras possibilidades devem ser levadas em conta, para permitir desvelar a forma específica que a narratividade assume num texto particular. Em primeiro lugar, é preciso notar que certas fases podem ser pressupostas. Se tomarmos o pequeno texto mencionado acima que relata que um faxineiro ganhou um milhão de dólares na Sena, veremos que estamos apenas narrando a performance. No entanto, há uma fase de competência pressuposta: só pode ganhar quem tem um bilhete, que é, por conseguinte, um poder ganhar. Em segundo lugar, é necessário destacar que certos textos dão mais ênfase a uma fase que a outras. Por exemplo, o programa Aqui e agora e uma novela policial do tipo inglês narram crimes. No entanto, a diferença da abordagem dos dois textos reside no fato de que aquele acentua a performance (como agiu o assassino, qual foi seu procedimento para matar a vítima, etc.), enquanto este evidencia a sanção (a descoberta da identidade do assassino pelo detetive). Em terceiro, cabe lembrar que uma narrativa complexa é constituída de inúmeras seqüências que se articulam por parataxe ou por hipotaxe, ou seja, uma pode-se colocar ao lado de outra ou estar subordinada a 
outra. Há uma relação hipotática entre as seqüências, por exemplo, na história da menina da bilha de leite. Há uma relação paratática, por exemplo, em contos maravilhosos em que o herói deve realizar inúmeras provas iniciáticas. Dizer que a narratologia formulada pela Semiótica é uma camisa de força ou que não se aplica a textos da literatura mais moderna é desconhecer os princípios dessa teoria narrativa.

Não é possível no espaço deste texto explicar toda a teoria narratológica que foi desenvolvida, a partir das formulações de Propp e de Lévi-Strauss, pela Semiótica francesa. O que importa é que se entendam os diferentes níveis de invariância do percurso gerativo de sentido. Há, porém, alguns elementos da semântica narrativa que devem ser destacados, depois de termos percorrido, de maneira muito sucinta, alguns aspectos da sintaxe narrativa.

O primeiro é que a Semiótica concebe os estados passionais como um arranjo de modalidades concernentes aos sujeitos. Essas modalidades pertencem ao componente semântico do nível narrativo. Assim, por exemplo, a curiosidade é a lexicalização de um querer saber. Evidentemente, essa é uma paixão cuja descrição é extremamente simples. Há outras que são bastante complexas, como, por exemplo, a cólera, o ressentimento.

Estão ainda no âmbito da semântica narrativa os conteúdos investidos nos objetos buscados pelos sujeitos. Assim, a riqueza nas histórias do Tio Patinhas, a notoriedade nas ações de Lilian Ramos ${ }^{2}$, o prazer nos 120 dias de Sodoma, de Sade. E exatamente nos conteúdos investidos nos objetos que se dá a articulação entre o nível fundamental e o nível narrativo. Os conteúdos do nível fundamental são concretizados nos objetos do nível narrativo.

É preciso responder agora uma dúvida, que deve estar presente na cabeça do leitor desde o momento em que leu que o percurso gerativo de sentido comporta um nível narrativo. Mas então todos os textos têm um nível narrativo? Para Semiótica, sim. É claro que é preciso entender narratividade como qualquer transformação de estado. Implícita ou explicitamente, todos os textos trabalham com transformações. Tomemos um que a teoria tradicional dos gêneros não poderia considerar, de maneira nenhuma, narrativo: um teorema. Esse texto articula-se em três partes: o enunciado do teorema, a demonstração e a afirmação de que a demonstração se fez (q.e.d., quod erat demonstrandum). Quando se faz a afirmação final, o que se está dizendo é que, no texto, se passou de um estado de não demonstrado para um de demonstrado. Teremos uma descrição, quando a transformação narrativa ficar implícita, ou seja, quando se trabalhar apenas com o estado inicial ou o estado final. Por isso, é que se diz que, na maioria dos casos, não temos descrições puras, que servem elas para iniciar um texto, que, em seguida, será mudado em narração. Teremos a narração, quando se enfocar a transformação propriamente dita. Assim, uma descrição passa a narração, quando se explicita a transformação que está implícita na descrição.

Passemos agora para o terceiro nível, o discursivo. Esse patamar é aquele

${ }^{2}$ Lembramos ainda uma vez que as narrativas são simulacros das ações do homem no mundo. 170 
em que se revestem as estruturas narrativas abstratas. Suponhamos que tivéssemos a seguinte estrutura narrativa Um sujeito A, que estava em conjunção com objeto vida, entra em disjunção com ele. Essa estrutura poderia ser concretizada como assassinato, se o sujeito operador da disjunção for concretizado como um ser humano diferente de A; como suicídio, se o sujeito operador da disjunção e A forem concretizados como a mesma personagem; como morte por acidente, se o sujeito operador for concretizado como um desastre ou uma catástrofe natural, etc. Esse é um primeiro nível de concretização. Depois, essa concretização primeira é suscetível de uma nova concretização. $\mathrm{O}$ assassinato pode ter sido um tiro dado por ladrões durante um roubo ou espancamento realizado por policiais numa Delegacia. Temos, então, dois níveis de concretização das estruturas narrativas: a tematização e a figurativização. Se a concretização parar no primeiro nível, teremos textos temáticos; se vier até o segundo, teremos textos figurativos. Os primeiros são compostos predominantemente de temas, isto é, de termos abstratos ${ }^{3}$; os segundos, preponderantemente de figuras, ou seja, de termos concretos. Cada um desses tipos de texto tem uma função diferente: os temáticos explicam o mundo; os figurativos, criam simulacros do mundo. Por exemplo, uma tese que discutisse a situação de penúria e as péssimas condições de trabalho dos operários franceses nas minas de carvão no século XIX, a questão da produção da mais valia e as lutas para melhorar essas condições de vida seria um texto temático; já o Germinal, de Zola, que trata desses mesmos assuntos, é um texto figurativo, pois faz uma representação de tudo isso. A dissertação é temática, enquanto a descrição e a narração são figurativas.

Compreender um texto figurativo é, antes de mais nada, entender o componente temático que subjaz às figuras. Nossa escola intuiu isso, pois freqüentemente se pede aos alunos que encontrem o tema do texto. O problema é que não se define para eles o que é tema, nem se ensinam as formas de encontrá-lo. Tudo é deixado por conta de uma certa sensibilidade, que um bom leitor deve ter. Ora, é claro que um bom leitor deve ter sensibilidade. No entanto, ela não é um dom divino, mas é algo que se constrói pela educação. Já Valéry dizia que o conhecimento precede o êxtase estético.

Voltemos ao percurso gerativo. Ele é composto de níveis de invariância crescente, porque um patamar pode ser concretizado pelo patamar imediatamente superior de diferentes maneiras, isto é, o patamar superior é uma variável em relação ao imediatamente inferior, que é uma invariante. A mesma estrutura

\footnotetext{
${ }^{3}$ A tradição escolar ensina que concreto/abstrato é uma categoria classificatória que se aplica aos substantivos. Na verdade, ela refere-se a todos os lexemas, pois abstrato é o termo que não remete a algo considerado existente no mundo natural, mas a uma categoria explicativa dos existentes, enquanto concreto é o termo que se refere a elementos existentes no mundo natural. É preciso entender bem o que significa mundo natural neste contexto, não é aquele mundo que os sentidos dão por natural, mas são os mundos que o discurso dá como existentes. Então, fada éconcreto, porque é considerado um ser existente no mundo natural criado pelo universo discursivo do conto maravilhoso. Já orgulho é uma categoria explicativa de uma série de atitudes concretas tomadas por seres efetivamente existentes em mundos naturais criados por universos de discurso. Da mesma forma, branco é um adjetivo concreto, enquanto terno é abstrato.
} 
narrativa, Um sujeito que entra em disjunção com o objeto vida, pode ser tematizada como assassinato, suicídio, morte por acidente, etc. $\mathrm{O}$ mesmo tema pode ser figurativizado de diferentes maneiras. Assim, o tema da evasão pode ser figuratizado pela ida para um mundo imaginário, como a Pasárgada cantada por Manuel Bandeira, ou por uma viagem pelos mares do sul. As fotonovelas e as telenovelas trabalham quase sempre com a mesma estrutura narrativa e geralmente com os mesmos temas (ascensão social, realização afetiva, etc.) figurativizados de maneira diferente.

A sintaxe do discurso compreende as projeções da enunciação no enunciado e os procedimentos que o enunciador utiliza para persuadir o enunciatário a aceitar o seu discurso. Aquelas abarcam a temporalização, a espacialização e a actorialização. Sendo a enunciação, como mostrava Benveniste, a instância do ego-hic-nunc, o processo de discursivização não existe sem a instauração de pessoas, espaços e tempos. Todas as pessoas, espaços e tempos instalados no enunciado estão de alguma forma relacionados ao eu-aqui-agora da enunciação. Além disso, há um componente aspectual, que projeta no discurso pontos de vista de um observador sobre as categorias enunciativas. ${ }^{4} \mathrm{O}$ que importa é determinar os efeitos de sentido gerados pelas diferentes projeções da enunciação no enunciado. Por exemplo, é preciso analisar qual é o efeito de sentido criado pela ausência do $e u$ no discurso narrativo, quando, então, como acontecia no naturalismo, os fatos parecem narrar-se por si mesmos. Por outro lado, ao recusar o ponto de vista da Teoria da Informação de que a comunicação é uma transmissão de novidades entre dois pólos neutros, a Semiótica considera que um componente determinante do processo comunicacional é o fazer crer. Por isso, o componente argumentativo adquire um relevo muito grande na teoria. Argumentação é qualquer mecanismo pelo qual o enunciador busca persuadir o enunciatário a aceitar seu discurso, a acolher o simulacro de si mesmo que cria no ato de comunicação.

Tomemos agora um texto para exemplificar essa descrição sumária do percurso gerativo de sentido. Assim como a exposição do percurso das estruturas $a$ quo às estruturas ad quem foi extremamente sucinto, a análise do texto também não é completa. Tem ela a finalidade de exemplificar apenas a passagem de um patamar a outro. Uma análise mais fina, como requer a teoria, não caberia nos limites deste texto.

\section{$O$ ferrageiro de Carmona}

Um ferrageiro de Carmona que me informava de um balcão:

"Aquilo? É de ferro fundido, foi a fôrma que fez, não a mão.

\footnotetext{
${ }^{4}$ Observe-se que a Semiótica trabalha com uma concepção ampliada de aspecto. Tradicionalmente, o aspecto era considerado um ponto de vista que sobredeterminava o tempo, indicando se o processo que se desenrolava no tempo era pontual ou durativo; em sendo durativo, se era contínuo ou descontínuo (iterativo), etc. Ora, numa perspectiva enunciativa, o aspecto é um ponto de vista que incide sobre cada uma das categorias da enunciação, a saber, o tempo, o espaço e a pessoa.
}

172 
Só trabalho em ferro forjado

que é quando se trabalha ferro;

então, corpo a corpo com ele,

domo-o, dobro-o, até o onde quero.

O ferro fundido é sem luta,

é só derramá-lo na fôrma.

Não há nele a queda-de-braço

e o cara-a-cara de uma forja.

Existe grande diferença

do ferro forjado ao fundido;

é uma distância tão enorme

que não pode medir-se a gritos.

Conhece a Giralda em Sevilha?

De certo subiu lá em cima.

Reparou nas flores de ferro

dos quatro jarros das esquinas?

Pois aquilo é ferro forjado.

Flores criadas numa outra língua.

Nada têm das flores de fôrma

moldadas pelas das campinas.

Dou-lhe aqui humilde receita

ao senhor que dizem ser poeta:

o ferro não deve fundir-se

nem deve a voz ter diarréia.

Forjar: domar o ferro à força, não até uma flor já sabida, mas ao que pode até ser flor se flor parece a quem o diga."

(MELLO Neto, 1987, p.31-32).

Vamos analisar o texto, indo das estruturas superficiais até as profundas e depois voltando. Inicialmente, observamos que ele trata do trabalho com o ferro. $\mathrm{O}$ ferrageiro explica que há duas maneiras de trabalhá-lo: a fundição e o forjamento. Na primeira, a fôrma ${ }^{5}$ faz o ferro adquirir uma forma; na segunda, é o ferreiro quem dá a forma. Nesta, o ferreiro realmente trabalha o ferro num corpo a corpo com ele, dando-lhe a forma que quer, enquanto, naquela, o ferro adquire a forma da fôrma. Esse nível em que se vai explicando o que é a fundição e o forjamento é o nível figurativo. Ainda na análise desse patamar, é preciso notar que há figuras que não se encaixam no plano de leitura proposto e, por isso, desencadeiam um segundo

\footnotetext{
${ }^{5}$ Vamos trabalhar com a oposição fôrma/forma. Ao fazê-lo, verificamos que o acento diferencial não é algo inútil, como apregoaram os eternos reformadores da ortografia. Para evitar ambigüidade, estamos restabelecendo o acento diferencial.
} 
plano. São elas língua, receita ao (...) poeta, voz. Essas figuras remetem ao campo léxico da linguagem. Pode-se então dizer que o segundo plano de leitura é o do trabalho com a linguagem. Neste, vemos que há duas maneiras de trabalhar a linguagem: a fundição, que deve ser lida como a construção de textos a partir de uma fórmula, e o forjamento, que deve ser concebido como a produção original de textos. Naquela, a linguagem (ferro) esparrama-se na fôrma; neste, ela é domada e adquire a forma que o poeta quer dar-lhe.

Nos dois planos de leitura, a fundição é apresentada como algo de valor negativo, que não se deve fazer ( ferro não deve fundir-se), porque nela não há originalidade (flores de fôrma moldadas pelas das campinas). $\mathrm{O}$ forjamento é o termo de valor positivo, pois é um trabalho original (Forjar: domar o ferro à força/não até uma flor já sabida,/mas ao que pode até ser flor/se flor parece a quem o diga). Ademais, o poeta liga a figura da fundição à da diarréia, o que pressupõe que o forjamento não está relacionado a ela. Esse entendimento permite agora organizar os diferentes patamares do percurso.

Esse texto constrói-se, no nível fundamental, com duas categorias de base: originalidade vs. habitualidade e moderação vs. excesso. Os primeiros termos das duas oposições são considerados eufóricos e os últimos, disfóricos.

No nível narrativo, aparece apenas a performance, ficando as demais fases da sequiência narrativa pressupostas. Na fundição, a fôrma é o sujeito operador que dá ao ferro ou à linguagem a forma; no forjamento, o sujeito operador é o ser humano. O objeto forma realiza uma primeira concretização das categorias fundamentais. A fôrma engendra uma forma já existente e diluída; o homem produz uma forma nova e concentrada.

A produção da primeira forma é tematizada como imitação e derramamento; a segunda, como criação e contenção. Os dois primeiros temas são figuratizados pela fundição e pela diarréia; os dois últimos, pelo forjamento e pela secura (esta figura está apenas pressuposta pelo discurso).

O texto, pois, considera negativa uma poética da imitação de formas e do derramamento e exalta a poética da criação de novas formas e da contenção.

Até agora analisamos o nível do conteúdo. No entanto, o conteúdo só pode manifestar-se por meio de um plano de expressão. No momento em que, no simulacro metodológico, temos a junção do plano de conteúdo com um plano de expressão, ocorre a textualização. O texto é, assim, uma unidade que se dirige para a manifestação. Seu conteúdo, engendrado por um percurso que vai do mais simples e abstrato ao mais complexo e concreto, manifesta-se por um plano de expressão. Aí, então, sofre a coerção do material que o veicula. Por exemplo, dado que o significante da linguagem verbal é linear, o conteúdo manifesto verbalmente será submetido à linearização.

O mais importante a notar, porém, é que na relação entre conteúdo e expressão gera-se o que chamamos efeitos estilísticos da expressão. Poderíamos dizer que temos basicamente textos com função utilitária (informar, convencer, explicar, documentar, etc.) e função estética. Não vamos discutir longamente as 
características de cada um desses textos. Vamos apenas apontar uma, que está vinculada à questão do plano de expressão. Se alguém ouve ou lê um texto com função utilitária não se importa com o plano de expressão. Ao contrário, atravessao e vai diretamente ao conteúdo, para entender a informação. No texto com função estética, a expressão ganha relevância, pois o escritor procura não apenas dizer o mundo, mas recriá-lo nas palavras, de tal sorte que importa não apenas o que se diz, mas o modo como se diz. Como o poeta recria o conteúdo na expressão, a articulação entre os dois planos contribui para a significação global do texto. A compreensão de um texto com função estética exige que se entenda não somente o conteúdo, mas também o significado dos elementos da expressão.

Dessa relevância do plano de expressão deriva uma segunda característica do texto com função estética, sua intangibilidade. Valéry, discutindo a diferença entre textos utilitários e estéticos, diz que, quando se faz um resumo do primeiro, apreende-se o essencial; já, quando se resume o segundo, perde-se o essencial.

Quem ler os seguintes versos de Os Lusíadas "Em tempo de tormenta e vento esquivo,"/“De tempestade escura e triste pranto" (V, 18, 3-4), sem perceber a aliteração de oclusivas e principalmente do " $t$ ", terá perdido um elemento essencial do texto, que é o efeito de sentido de fúria da tormenta, dado pela articulação entre a aliteração no plano da expressão e o conteúdo manifestado.

Um texto pode trabalhar melhor um nível que outro, um componente do que outro. Por isso, é sobre esse aspecto mais explorado que a análise deve centrarse.

As teorias do discurso nem sempre são reconhecidas pelos praticantes dos chamados núcleos duros da Lingüística como prática científica. Muitos negam que o uso lingüístico seja um objeto tão válido quanto os demais. Acresce a isso que, muitas vezes, trava-se uma verdadeira guerra entre os estudiosos do discurso. As diferentes teorias são distintas é verdade, mas não se anulam, pois tratam de aspectos complementares do processo de constituição do sentido. Aliás, não poderia ser diferente, dado que o objeto com que trabalhamos é extremamente complexo. Sirva para nós a lição de Riobaldo:

Todos estão loucos, neste mundo? Porque a cabeça da gente é uma só, e as coisas que há e que estão para haver são demais de muitas, muito maiores diferentes, e a gente tem que necessitar de aumentar a cabeça para o total.

\section{BIBLIOGRAFIA}

BARROS, Diana Luz Pessoa de. Teoria do discurso: fundamentos semióticos. São Paulo, Atual, 1988.

GREIMAS, A. J. Maupassant. La sémiotique du texte: exercices pratiques. Paris, Seuil, 1976.

GREIMAS, A. J.; COURTES, J. Sémiotique. Dictionnaire raisonné de la théorie 
du langage. Paris, Hachette, 1979.

MELlO Neto, João Cabral de. Crime na calle Relator. Rio de Janeiro, Nova Fronteira, 1987. 